Check for updates

Cite this: RSC Adv., 2019, 9, 14809

Received 3rd March 2019

Accepted 8th May 2019

DOI: 10.1039/c9ra01593k

rsc.li/rsc-advances

\section{Synthesis and high formaldehyde sensing properties of quasi two-dimensional mesoporous $\mathrm{ZnSnO}_{3}$ nanomaterials}

\author{
Bingshan Wang, (D)*a Jinbao Yu, ${ }^{a}$ Xiaohong Li, ${ }^{b}$ Jun Yin ${ }^{a}$ and Meng Chen ${ }^{a}$ \\ Quasi two-dimensional (2D) mesoporous $\mathrm{ZnSnO}_{3}$ nanomaterials (QTMZNS) were synthesized by a simple \\ template-free hydrothermal method. The as-prepared products were characterized by TEM, SEM, XRD, TG/ \\ DTA, and FTIR. The results showed that the precursor was a mixture of $\mathrm{Zn}_{5}(\mathrm{OH})_{6}\left(\mathrm{CO}_{3}\right)_{2}$ and $\mathrm{ZnSnO}_{3}$ in the \\ hydrothermal process, and the high purity QTMZNS were obtained by calcination combined with \\ subsequent washing of $20 \mathrm{wt} \% \mathrm{NH}_{4} \mathrm{Cl}$ solutions. A possible growth process and mechanism of the quasi \\ 2D mesoporous structure was proposed. Gas sensing properties of QTMZNS were investigated, and the \\ QTMZNS-based sensors exhibited excellent gas sensing properties. When exposed to $100 \mathrm{ppm}$ \\ formaldehyde vapors, the response sensitivity is 45.8, and the concentration limit can reach as low as \\ $0.2 \mathrm{ppm}$ of formaldehyde. All these results are much better than those reported so far, which will have \\ great potential applications for practical air quality monitoring.
}

\section{Introduction}

Nanomaterials with porous structure have good potential applications in many fields, such as photocatalysis, ${ }^{\mathbf{1}}$ super capacitors, ${ }^{2}$ drug delivery, ${ }^{3}$ lithium storage, ${ }^{4}$ gas sensing, ${ }^{5,6}$ and surface-enhanced Raman scattering (SERS). ${ }^{7,8}$ 2D sheet-like mesoporous materials with unique structural advantages have intriguing properties, attractive applications, as well as environmental and industrial benefits. ${ }^{\mathbf{9}-11}$ Therefore, different kinds of mesoporous nanosheets materials were fabricated and have already achieved good success in many fields in recent years. ${ }^{\mathbf{1 2 - 1 6}}$

In comparison to single metal oxides, composite metal oxides would have more superior properties than single metal oxides by altering the compositions. ${ }^{17-19}$ Therefore, the fabrication of composite metal oxides has attracted an increasing interest. $\mathrm{ZnSnO}_{3}$, as an important ternary semiconducting oxide, has been used widely in gas sensing fields, due to its high chemical response and excellent electronic properties. ${ }^{20-27}$ Because of its outstanding properties, $\mathrm{ZnSnO}_{3}$ has attracted extensive interest during the past few years, especially in terms of the synthesis of nanostructures. Until now, some $\mathrm{ZnSnO}_{3}$ porous structures such as porous $\mathrm{ZnSnO}_{3}$ hollow microspheres, ${ }^{22}$ porous $\mathrm{ZnSnO}_{3}$ hollow nanocubes, ${ }^{23,24}$ mesoporous $\mathrm{ZnSnO}_{3}$ cubes, ${ }^{26}$ and mesoporous $\mathrm{ZnSnO}_{3}$ nanocrystals ${ }^{27}$ have been successfully fabricated, whereas controlled synthesis of quasi two-dimensional mesoporous $\mathrm{ZnSnO}_{3}$ nanomaterials

${ }^{a}$ Department of Bio-chemistry, Jingdezhen University, Jingdezhen, Jiangxi, 333000, China.E-mail:wbs31@163.com

${ }^{b}$ National Engineering Research Center for Domestic \& Building Ceramics, Jingdezhen Ceramic Institute, Jingdezhen, Jiangxi, 333000, China have not been reported. Lamellar nanosheet structure could endow the good stability of the material compared with nanoparticles due to the decreased surface energies, and stable nanosheet structure can ensure the stability of gas sensitive test results which can be seen in previous literatures. ${ }^{28,29}$ Porous structure is beneficial to gas diffusion and mass transport, ${ }^{30,31}$ the existence of defects such as oxygen vacancies could increase the chance of electrostatic interaction between testing gas and the surface of sensing materials, benefiting to oxygen adsorption and further enhance the gas response of the sensors. ${ }^{32}$ So, it is of significant value to develop porous $\mathrm{ZnSnO}_{3}$ nanosheets sensors.

In this paper, we adopted a general template-free hydrothermal method with subsequent calcination and washing of $20 \mathrm{wt} \% \quad \mathrm{NH}_{4} \mathrm{Cl}$ solutions for synthesis QTMZNS. The morphology, chemical composition, crystalline structure and thermal behavior of as-prepared products were characterized by SEM, TEM, XRD, and so on. Meanwhile, the formation mechanism has been investigated through the morphology evolution with different procedure. In addition, the formaldehyde sensing properties of the QTMZNS-based sensors were systematically studied. It is worth mentioning that the procedure for producing QTMZNS can easily be scaled-up, which is particularly attractive for industrial applications.

\section{Experimental}

\subsection{Materials synthesis}

All chemical reagents used in this experiment were of analytical grade and used without further purification. A typical synthesis procedure of the QTMZNS was as follows: $1.73 \mathrm{~g}$ of $\mathrm{SnCl}_{4} \cdot 5 \mathrm{H}_{2} \mathrm{O}$, 
$1.488 \mathrm{~g}$ of $\mathrm{Zn}\left(\mathrm{NO}_{3}\right)_{2}$, and $1.802 \mathrm{~g}$ of $\mathrm{CO}\left(\mathrm{NH}_{2}\right)_{2}$ were dissolved in $80 \mathrm{ml}$ of deionized water together under magnetic stirring for $10 \mathrm{~min}$ at room temperature. Then the mixed solution was transferred to a Teflon-lined stainless steel autoclave and maintained at $130{ }^{\circ} \mathrm{C}$ for $16 \mathrm{~h}$. After natural cooling, the precursor was filtered, washed with distilled water and alcohol for several times, and finally dried in air at $70{ }^{\circ} \mathrm{C}$. The assynthesized precursor was calcined at $500{ }^{\circ} \mathrm{C}$ for $3 \mathrm{~h}$, and then washed by $20 \mathrm{wt} \% \mathrm{NH}_{4} \mathrm{Cl}$ solutions for $10 \mathrm{~min}$, filtered, washed with distilled water, and dried, thus the high purity QTMZN were obtained.

\subsection{Characterization}

The crystal phase, morphology and microstructure of the synthesized samples were characterized by X-ray diffraction (XRD: Bruker D8-Advance X-ray diffractometer, with highintensity $\mathrm{Cu} \mathrm{K}_{\alpha 1}$ radiation, $\lambda=1.5406 \AA$ ), Fourier transform infrared spectroscopy (FTIR, IR Prestige-21), field emission scanning electron microscopy (FE-SEM, Hitachi S-4800), and transmission electron microscopy (TEM; JSM-2010 HR, Japan). The pore diameter distribution and surface area of the products were tested by nitrogen adsorption/desorption analysis (Micromeritics ASAP 2020). Thermogravimetric and differential scanning calorimetry (TG-DSC) was performed on a NETZSCH STA449C thermogravimetric analyzer from 50 to $800{ }^{\circ} \mathrm{C}$ at a heating rate of $10{ }^{\circ} \mathrm{C} \min ^{-1}$ in $\mathrm{N}_{2}$ flow.

\subsection{Fabrication and measurement of gas sensor}

In order to study the gas sensing properties of the QTMZNS, gas sensors were obtained by coating the QTMZNS paste onto the surface of the ceramic tube with a pair of gold electrodes printed previously, and then a Cr-Ni alloy coil through the tube was used as a heater to form a side-heated gas sensor. Subsequently, the sensors were calcined at $460{ }^{\circ} \mathrm{C}$ for $3 \mathrm{~h}$. Finally, in order to improve the long-term stability, the sensors were aged with $300{ }^{\circ} \mathrm{C}$ heating for 20 days. The gas-sensing properties of the QTMZNS were measured using a sensor tester of WS-30A (Weisheng Instruments Co., Ltd., China). The desired concentrations of the testing gases were obtained by the static liquid gas distribution method, which was calculated by the formula $\left(C \times 10^{-6}=n R T / 0.018 P\right.$. $P$ : atmospheric pressure; $T$ : room temperature; $0.018 \mathrm{~m}^{3}$ : the test chamber volume). In the gas response measurement, specified testing liquid was injected into the closed $18 \mathrm{~L}$ chamber through the injection pore and mixed with air. After the measurement, the sensor was exposed to the atmospheric air by opening the closed chamber to return to its initial state. The data were collected by a computer automatically. The gas response $(S)$ was defined as the ratio of $R_{\mathrm{a}} / R_{\mathrm{g}}$ ( $R_{\mathrm{a}}$ : the resistance of the sensor in air; $R_{\mathrm{g}}$ : the resistance of the sensor in testing gases). The recovery time and response time were defined as the time taken by the sensor to achieve $90 \%$ of the total resistance change during gas desorption and adsorption phase, respectively.

\section{Results and discussion}

\subsection{Structure and morphology characterization}

The high purity quasi two-dimensional mesoporous $\mathrm{ZnSnO}_{3}$ nanomaterials (QTMZNS) were obtained through a three-step procedure. First, the mixture precursor of $\mathrm{Zn}_{5}\left(\mathrm{CO}_{3}\right)_{2}(\mathrm{OH})_{6}$ and $\mathrm{ZnSnO}_{3}$ was derived from hydrothermal reaction process. Second, calcination of the mixture precursor could yield the mixed oxide of $\mathrm{ZnO}$ and $\mathrm{ZnSnO}_{3}$. Then the high purity sheet-like mesoporous $\mathrm{ZnSnO}_{3}$ nanomaterials were obtained by washing the corresponding calcined product with $20 \mathrm{wt} \% \mathrm{NH}_{4} \mathrm{Cl}$ solutions for $10 \mathrm{~min}$. Fig. 1 shows the XRD patterns of the precursor before annealing (Fig. 1(a)), after annealing at $500{ }^{\circ} \mathrm{C}$ for $3 \mathrm{~h}$ (Fig. 1(b)), and the final products which obtained by washing the corresponding calcined product with $20 \mathrm{wt} \% \mathrm{NH}_{4} \mathrm{Cl}$ solutions for $10 \mathrm{~min}$ (Fig. 1(c)). From Fig. 1(a), the peaks in the XRD pattern can be well indexed to both the orthorhombic phase of $\mathrm{ZnSnO}_{3}$ (JCPDS no. 28-1486) ${ }^{21}$ and the monoclinic phase of $\mathrm{Zn}_{5}\left(\mathrm{CO}_{3}\right)_{2}(\mathrm{OH})_{6}$ (JCPDS no. 19-1458), ${ }^{33}$ which indicating that the precursor was the mixture of $\mathrm{Zn}_{5}\left(\mathrm{CO}_{3}\right)_{2}(\mathrm{OH})_{6}$ and $\mathrm{ZnSnO}_{3}$. For the precursor heat-treated at $500{ }^{\circ} \mathrm{C}$ for $3 \mathrm{~h}$, the diffraction peaks including both $\mathrm{ZnO}$ (JCPDS no. 80-0074) ${ }^{33}$ and $\mathrm{ZnSnO}_{3}$ could be observed in Fig. 1(b), which was related to the mixed oxide of $\mathrm{ZnO}$ and $\mathrm{ZnSnO}_{3}$. As shown in Fig. 1(c), all diffraction peaks in the XRD pattern can be well-assigned to the standard pattern of $\mathrm{ZnSnO}_{3}$ (JCPDS no. 28-1486). ${ }^{21}$ No impurity phases are detected, which indicates that the final products are pure orth- $\mathrm{ZnSnO}_{3}$.

To trace the composition of the precursor and the formation history of $\mathrm{ZnSnO}_{3}$ during calcinations and washing with $20 \mathrm{wt} \%$ $\mathrm{NH}_{4} \mathrm{Cl}$, TG/DTA and the FTIR spectra investigations were also carried out. Fig. 2 recorded the TG-DTA curve of the mixture precursor $\left(\mathrm{Zn}_{5}\left(\mathrm{CO}_{3}\right)_{2}(\mathrm{OH})_{6}\right.$ and $\left.\mathrm{ZnSnO}_{3}\right)$, which carried out under $\mathrm{N}_{2}$ atmosphere, and the detected temperature range is from $50{ }^{\circ} \mathrm{C}$ to $800{ }^{\circ} \mathrm{C}$ at a heating rate of $10{ }^{\circ} \mathrm{C} \mathrm{min}{ }^{-1}$. The TGDTA curves clearly show the mixture precursor has three weight loss steps in the detected temperature range. Obviously, the

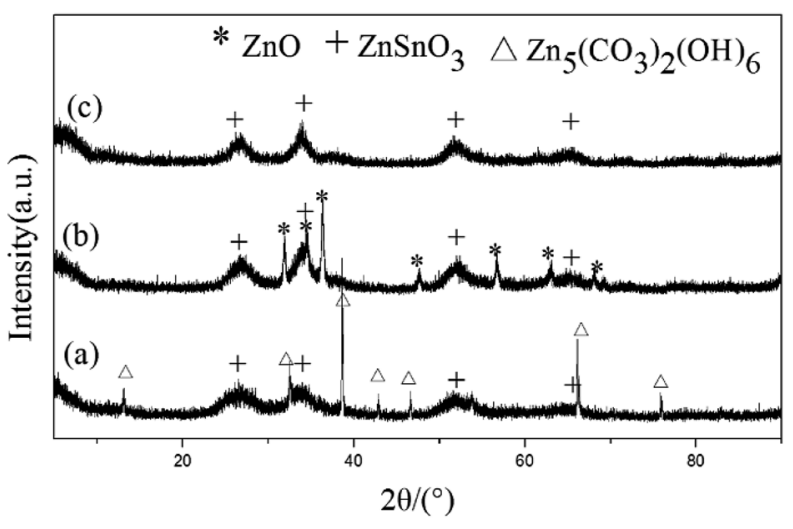

Fig. 1 XRD patterns of the precursor (a) before annealing, (b) after annealing at $500{ }^{\circ} \mathrm{C}$ for $3 \mathrm{~h}$, and (c) corresponding calcined product washed with $20 \mathrm{wt} \% \mathrm{NH}_{4} \mathrm{Cl}$ solutions for $10 \mathrm{~min}$. $\mathrm{ZnSnO}_{3}, \mathrm{Zn}_{5}(-$ $\left.\mathrm{CO}_{3}\right)_{2}(\mathrm{OH})_{6}$, and $\mathrm{ZnO}$ peaks are marked with plus sign, triangular symbol, and asterisks respectively. 


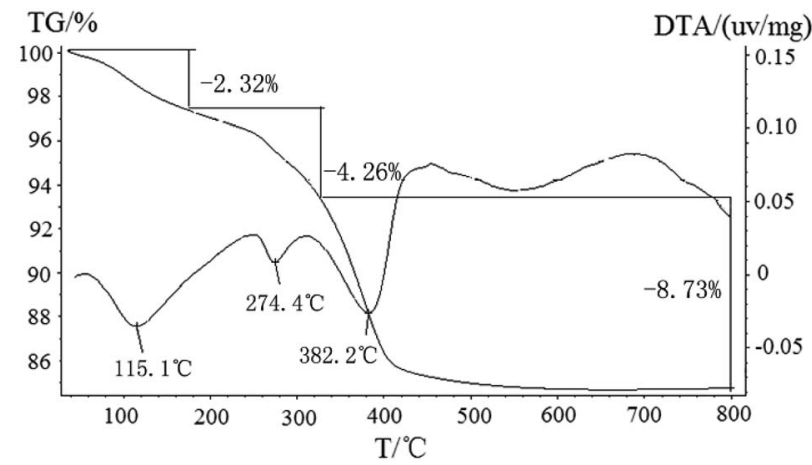

Fig. 2 TG and DTA curves of the mixture precursor of $\left(\mathrm{Zn}_{5}\left(\mathrm{CO}_{3}\right)_{2}(-\right.$ $\mathrm{OH})_{6}$ and $\mathrm{ZnSnO}_{3}$ ) at a heating rate of $10^{\circ} \mathrm{C} \mathrm{min}^{-1}$ in $\mathrm{N}_{2}$.

precursor before $150{ }^{\circ} \mathrm{C}$ has a weight loss, which is mainly attributed to residual moisture removing from the sample in pre-drying stage. After $150{ }^{\circ} \mathrm{C}$, the TG-DTA curves show two weight loss in the temperature range of $150-500{ }^{\circ} \mathrm{C}$ with endothermic peaks at $274.4{ }^{\circ} \mathrm{C}$ and $382.2{ }^{\circ} \mathrm{C}$, which can be attributed to the thermal decomposition of the precursor from $\mathrm{Zn}_{5}\left(\mathrm{CO}_{3}\right)_{2}(\mathrm{OH})_{6} / \mathrm{ZnSnO}_{3}$ to $\mathrm{ZnO} / \mathrm{ZnSnO}_{3}$. The reaction equations are as follows:

$$
\begin{aligned}
\mathrm{Zn}_{5}\left(\mathrm{CO}_{3}\right)_{2}(\mathrm{OH})_{6} & \rightarrow 3 \mathrm{ZnO} \cdot 2 \mathrm{ZnCO}_{3}+3 \mathrm{H}_{2} \mathrm{O}(4.26 \text { mass loss } \%)(1) \\
3 \mathrm{ZnO} \cdot 2 \mathrm{ZnCO}_{3} & \rightarrow \mathrm{ZnO}+2 \mathrm{CO}_{2} \uparrow(8.73 \text { mass loss } \%)
\end{aligned}
$$

The value of total weight loss in this process was about $12.99 \%$, which was not consistent with the theoretical value (25.96\%). The result of the TG-TDA show there was other matter in the precursor, and which was consistent with the XRD results above. In the FTIR spectra shown in Fig. 3(a), the band at $3221 \mathrm{~cm}^{-1}$ was attributed to the bending vibration and stretching vibration modes of $\mathrm{OH}$ group in the structure of $\mathrm{Zn}_{5}\left(\mathrm{CO}_{3}\right)_{2}(\mathrm{OH})_{6}$. The band at $869 \mathrm{~cm}^{-1}$ was the stretching vibration of carbonyl group $(\mathrm{C}=\mathrm{O})$ for $\mathrm{CO}_{3}{ }^{2-}{ }^{24,35}$ The band

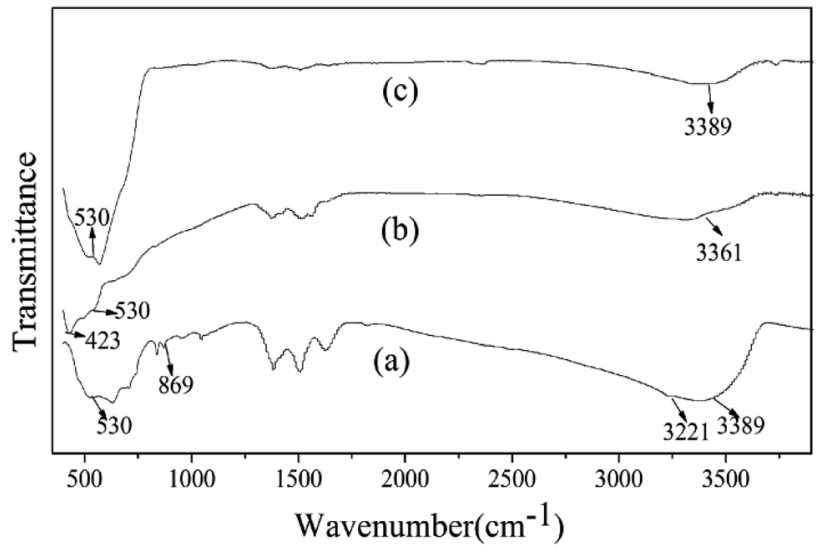

Fig. 3 FTIR data of the precursors (a) before annealing, (b) after annealing at $500{ }^{\circ} \mathrm{C}$ for $3 \mathrm{~h}$, and (c) corresponding calcined product washed with $20 \mathrm{wt} \% \mathrm{NH}_{4} \mathrm{Cl}$ solutions for $10 \mathrm{~min}$. observed at $530 \mathrm{~cm}^{-1}$ was assigned to vibrations of $\mathrm{Sn}-\mathrm{O}$ group for $\mathrm{ZnSnO}_{3}{ }^{21,46}$ After calcination, the precursor at the peaks of the hydroxyl group and carbonyl group almost disappeared. And the band at $423 \mathrm{~cm}^{-1}$ which was assigned to stretching vibrations of $\mathrm{Zn}-\mathrm{O}$ group for $\mathrm{ZnO}$ was shown in Fig. $3(\mathrm{~b}) .^{34,35}$ However, the band at $423 \mathrm{~cm}^{-1}$ has disappeared in Fig. 3(c) when the corresponding calcined product washed with $20 \mathrm{wt} \%$ $\mathrm{NH}_{4} \mathrm{Cl}$ solutions for $10 \mathrm{~min}$, indicating the loss of the $\mathrm{ZnO}$, and then also proved that the final product is pure $\mathrm{ZnSnO}_{3}$, which is also consistent with the XRD results above. In addition, a much weaker broad peak at about $3380 \mathrm{~cm}^{-1}$ (Fig. 3(a)-(c)) is attributed to surface absorbed water after drying.

The morphology, structure and chemical composition of the as-formed $\mathrm{ZnSnO}_{3}$ were illuminated by SEM, TEM and HRTEM. The overall morphology of the sample, as shown in Fig. 4(a) and (b), indicates the irregular sheet-like structures which were randomly stacked together. The surface of the irregular sheetlike structures with lots of interspaces was composed of many tiny nanoparticles. Its typical TEM and HRTEM images, as shown in Fig. 4(c) and (d), further depict the sheet-like morphology and mesoporous structures of the pure $\mathrm{ZnSnO}_{3}$ which are uneven in thickness and uneven in size. The HRTEM image demonstrates that the quasi two-dimensional mesoporous $\mathrm{ZnSnO}_{3}$ nanomaterials (QTMZNS) were composed of many tiny nanoparticles with 5-10 nm size, and QTMZNS have nanopores in the main range $2-12 \mathrm{~nm}$, which means that the QTMZNS could have larger active surfaces.,36 Mainly, two sets of lattice spacings of $3.34 \AA$ and $2.64 \AA$ are observed, which correspond to (012) and (110) planes of orth- $\mathrm{ZnSnO}_{3}$, respectively. The inset in Fig. 4(c) shows the SAED pattern of the QTMZNS, indicating its polycrystalline nature, which further confirms the HRTEM's observation.

\subsection{Growth process and mechanism}

To understand the formation process and the possible growth mechanism of the QTMZNS, the morphology, structure and chemical composition of the mixture precursor
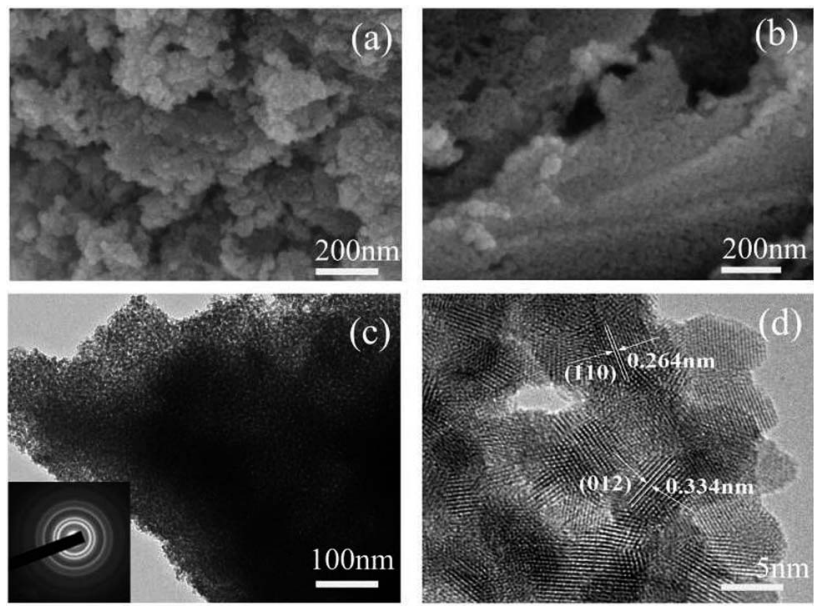

Fig. 4 (a) and (b) SEM image, (c) TEM image, (d) HRTEM image of the pure $\mathrm{ZnSnO}_{3}$. 
$\left(\mathrm{Zn}_{5}\left(\mathrm{CO}_{3}\right)_{2}(\mathrm{OH})_{6}\right.$ and $\left.\mathrm{ZnSnO}_{3}\right)$ before and after calcination were also studied, as shown in Fig. 5. Fig. 5(a) is a typical lowmagnification SEM image of the mixture precursor which obtained by a hydrothermal method at $130{ }^{\circ} \mathrm{C}$ for $16 \mathrm{~h}$, from which some quasi sandwich structure or layer-like structure were observed. A high-magnification SEM image and TEM image are shown in Fig. 5(b) and (c), which further depict the quasi sandwich structure of the mixture precursor. The quasisandwich structure is composed of nanosheets and irregular mesoporous sheet-like nanomaterials, and most of them alternate in turn. Fig. 5(d)-(f) are SEM images and a TEM image of the mixture precursor after an annealing treatment at $500{ }^{\circ} \mathrm{C}$ for $3 \mathrm{~h}$. By contrast, the morphology and structure of the mixture precursor has almost no change before and after the calcination, except for the porous in the nanosheets. According to the above analysis results, including the Fig. 4 above, it is not difficult to find that the nanosheets morphology belongs to $\mathrm{Zn}_{5}\left(\mathrm{CO}_{3}\right)_{2}(\mathrm{OH})_{6}$ in Fig. 5(a)-(c), the porous nanosheets are $\mathrm{ZnO}$ in Fig. 5(d)-(f), and the quasi 2D mesoporous materials are $\mathrm{ZnSnO}_{3}$ in Fig. 4 and 5 .

On the basis of the above analysis results, a formation mechanism of the QTMZNS could be proposed here. A possible growth process was schematically illustrated in Fig. 6 though the exact mechanism was still unclear at present. The synthesis consists of three steps-hydrothermal process, annealing process and washing process with $20 \mathrm{wt} \% \mathrm{NH}_{4} \mathrm{Cl}$ solutions. These processes may be explained by the following sequence of reactions:

$$
\mathrm{CO}\left(\mathrm{NH}_{2}\right)_{2}+\mathrm{H}_{2} \mathrm{O} \rightarrow 2 \mathrm{NH}_{3} \uparrow+\mathrm{CO}_{2} \uparrow
$$
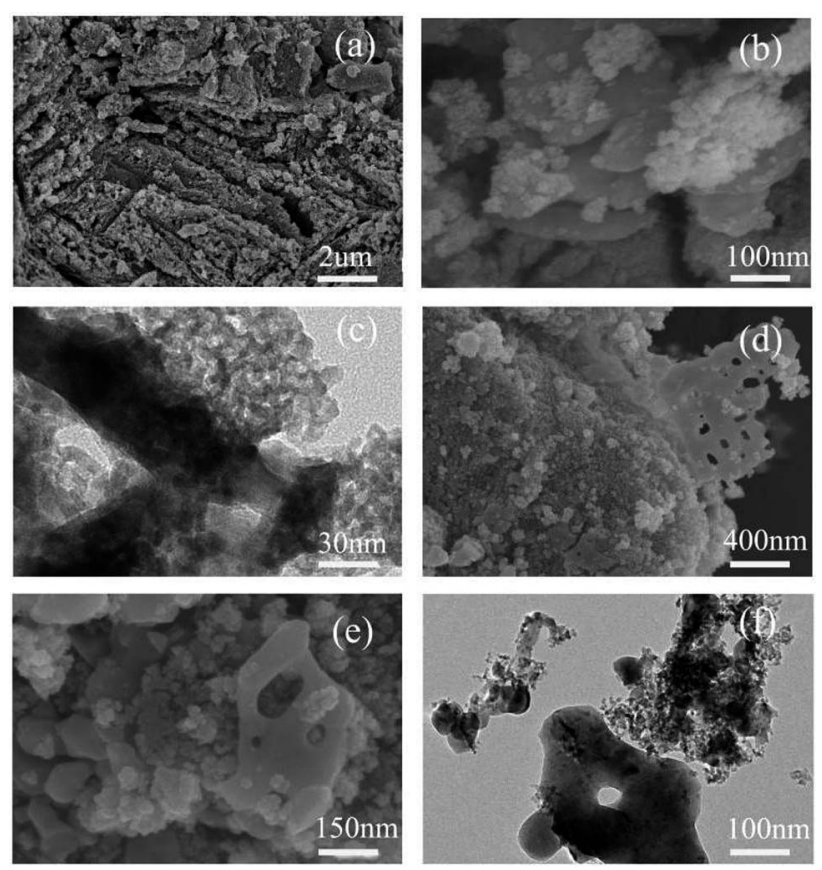

Fig. 5 (a) Low, (b) high magnification SEM images and (c) TEM image of the mixture precursor. (d) Low, (e) high magnification SEM images and (f) TEM image of the mixture precursor after an annealing treatment at $500{ }^{\circ} \mathrm{C}$.

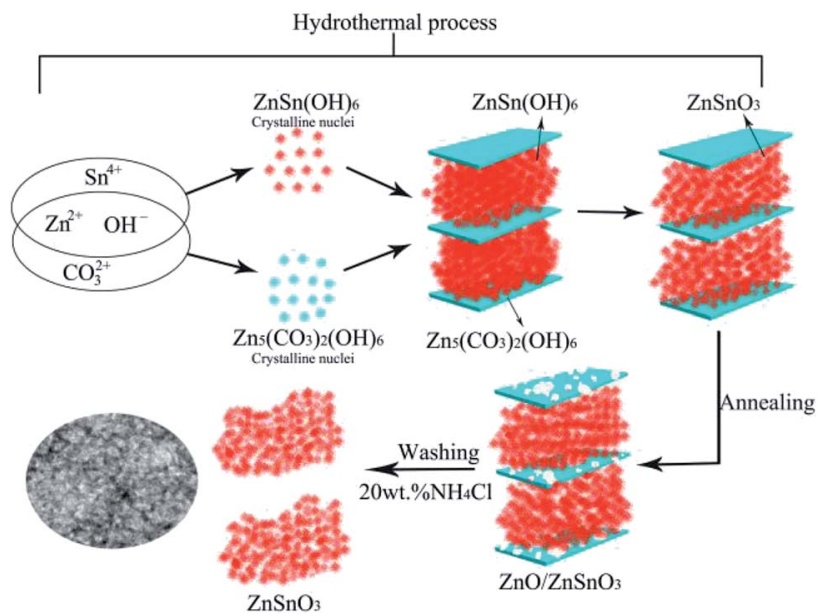

Fig. 6 Schematic illustration for the possible formation process of QTMZNS.

$$
\begin{gathered}
\mathrm{NH}_{3}+\mathrm{H}_{2} \mathrm{O} \rightarrow \mathrm{NH}_{4}^{+}+\mathrm{OH}^{-} \\
\mathrm{CO}_{2}+2 \mathrm{OH}^{-} \rightarrow \mathrm{CO}_{3}^{2-}+\mathrm{H}_{2} \mathrm{O} \\
5 \mathrm{Zn}^{2+}+2 \mathrm{CO}_{3}^{2-}+6 \mathrm{OH}^{-} \rightarrow \mathrm{Zn}_{5}\left(\mathrm{CO}_{3}\right)_{2}(\mathrm{OH})_{6} \downarrow \\
\mathrm{Zn}^{2+}+\mathrm{Sn}^{4+}+\mathrm{OH}^{-} \rightarrow \mathrm{ZnSn}(\mathrm{OH})_{6} \downarrow \rightarrow \mathrm{ZnSnO}_{3} \downarrow+\mathrm{H}_{2} \mathrm{O} \\
\mathrm{Zn}_{5}\left(\mathrm{CO}_{3}\right)_{2}(\mathrm{OH})_{6} \rightarrow 5 \mathrm{ZnO}+2 \mathrm{CO}_{2} \uparrow+3 \mathrm{H}_{2} \mathrm{O} \\
\mathrm{NH}_{4}^{+}+\mathrm{H}_{2} \mathrm{O} \rightarrow \mathrm{H}^{+}+\mathrm{NH}_{4} \mathrm{OH} \\
2 \mathrm{H}^{+}+\mathrm{ZnO} \rightarrow \mathrm{Zn}^{2+}+\mathrm{H}_{2} \mathrm{O}
\end{gathered}
$$

In the hydrothermal process, urea could produce $\mathrm{OH}^{-}$ anions and $\mathrm{CO}_{3}{ }^{2-}$ anions, which would react with the $\mathrm{Zn}^{2+}$ cations to form insoluble $\mathrm{Zn}_{5}(\mathrm{OH})_{6}\left(\mathrm{CO}_{3}\right)_{2}$. Numerous studies have shown that the crystal structure of the metallic basic salt with the molecular composition of $\mathrm{M}_{a}(\mathrm{OH})_{b}\left(\mathrm{X}^{c-}\right)_{(2 a-b) / c}(\mathrm{M}=$ $\mathrm{Zn}^{2+}, \mathrm{Co}^{2+}, \mathrm{Ni}^{2+}$, and so on) is sheets, ${ }^{37-39}$ and researchers have prepared a variety of two-dimensional porous $\mathrm{ZnO}$ nanomaterials using this principle in recent years. ${ }^{40-43}$ At the same time, $\mathrm{OH}^{-}$anions and $\mathrm{Zn}^{2+}$ cations would also react with the $\mathrm{Sn}^{2+}$ cations to form $\mathrm{ZnSn}(\mathrm{OH})_{6}$ between sheets of $\mathrm{Zn}_{5}(\mathrm{OH})_{6}(-$ $\left.\mathrm{CO}_{3}\right)_{2}$, which decomposed into orth- $\mathrm{ZnSnO}_{3}$ under the hydrothermal condition, and the quasi $2 \mathrm{D}$ mesoporous orth- $\mathrm{ZnSnO}_{3}$ nanomaterials are formed immediately. The reactions can be expressed by eqn (3)-(7). In the annealing process, the $\mathrm{Zn}_{5}(-$ $\mathrm{OH})_{6}\left(\mathrm{CO}_{3}\right)_{2}$ could be decomposed into wurtzite $\mathrm{ZnO}$ after further annealing at $500{ }^{\circ} \mathrm{C}$ for $3 \mathrm{~h}$. Due to the loss of volatile gas such as $\mathrm{H}_{2} \mathrm{O}$ and $\mathrm{CO}_{2}$ released during the annealed process, the $\mathrm{ZnO}$ nanosheets with porous structure were formed, which could be expressed by eqn (8). In the washing process with $20 \mathrm{wt} \% \mathrm{NH}_{4} \mathrm{Cl}$ solutions, the hydrolysis of $\mathrm{NH}_{4} \mathrm{Cl}$ produced a suitable acidic environment that was just capable of reacting with $\mathrm{ZnO}$ rather than $\mathrm{ZnSnO}_{3}$, which could be expressed by eqn (9) and (10). So after the three synthesis steps, the final products 
were pure quasi $2 \mathrm{D}$ mesoporous orth- $\mathrm{ZnSnO}_{3}$ nanomaterials. In our synthesis process, neither the soft template nor the hard template was used, but the nanosheets $\mathrm{Zn}_{5}(\mathrm{OH})_{6}\left(\mathrm{CO}_{3}\right)_{2}$ formed in the hydrothermal process played the role of template. This method was worthy of reference and recommendation.

\subsection{Gas sensing properties of QTMZNS}

To the semiconductor oxide sensors, gas sensing properties depend strongly on the working temperature. Fig. 7(a) shows response versus working temperature of the QTMZNS-based sensors exposed to $50 \mathrm{ppm}$ HCHO. It can be seen that the response to formaldehyde increased with the increase of working temperature from 170 to $210{ }^{\circ} \mathrm{C}$, and reached maximum response value at $210{ }^{\circ} \mathrm{C}$. After that, the response value decreased with increasing temperature. Therefore, the optimum working temperature of the sensors based on QTMZNS could be selected as $210^{\circ} \mathrm{C}$. The long-term stability of a gas sensor is necessary for practical applications. Good stability or good reproducibility needs the reliability guarantee of the material. The results in Fig. 7(b) showed that the QTMZNS-based sensor tended to remain relatively stable during a long-term stability measurement of 60 days. The QTMZNSbased sensor showed a decrease of about $1.5 \%$, implying a good reliability, which also indicated that the QTMZNS-based sensors obtained good repeatability for HCHO detection. Fig. 8 displays the response of QTMZNS to different concentration of formaldehyde gas at the working temperature of $210^{\circ} \mathrm{C}$. It can be seen that the QTMZNS-based sensor provided a stable baseline in the air condition. After HCHO was injected, the QTMZNS-based sensor got a positive response. When the
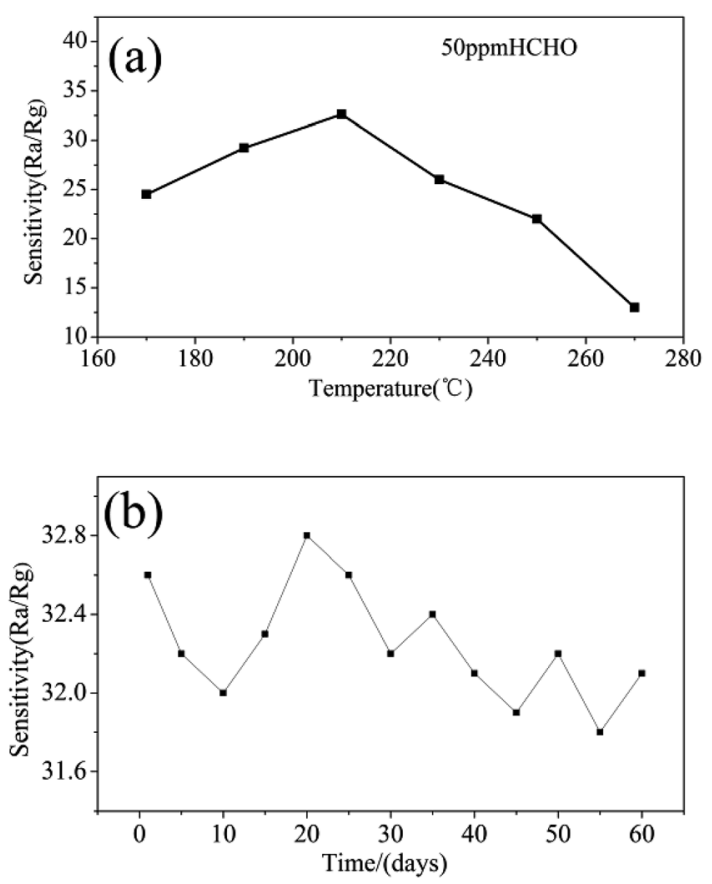

Fig. 7 (a) Response versus working temperature of the QTMZNSbased sensor exposed to $50 \mathrm{ppm} \mathrm{HCHO}$, (b) long-term stability of the QTMZNS-based sensor exposed to $50 \mathrm{ppm} \mathrm{HCHO}$ at $210^{\circ} \mathrm{C}$.
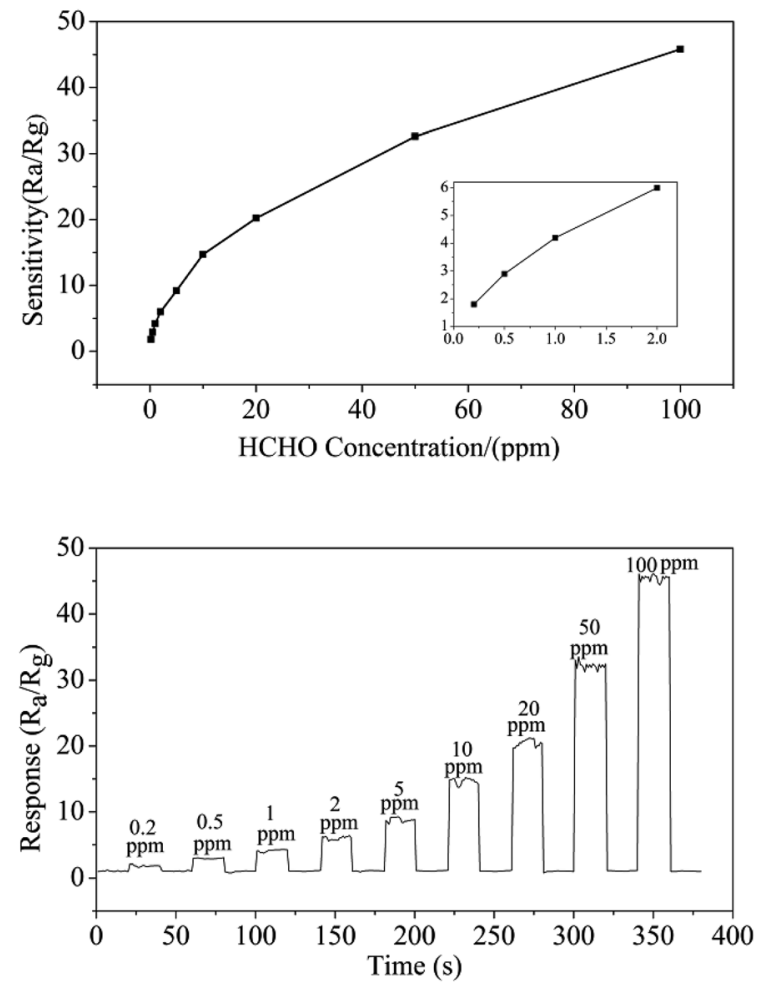

Fig. 8 The response of QTMZNS to different concentration of formaldehyde gas at the working temperature of $210^{\circ} \mathrm{C}$.

QTMZNS-based sensor was exposed in air again, it presented a recovery characteristic. With the corresponding formaldehyde gas concentration increasing, the response of the QTMZNSbased sensor increased. The response of the sensor based on QTMZNS to $0.2,0.5,1,2,5,10,20,50$, and 100 ppm were 1.8, $2.9,4.2,6.0,9.2,14.7,20.2,32.6$, and 45.8 , respectively.

The response/recovery time is an important parameter for the application of gas sensors. ${ }^{44}$ Fig. 9(a) shows the response/ recovery time graph of the QTMZNS-based sensor to $0.2 \mathrm{ppm}$ formaldehyde at $210{ }^{\circ} \mathrm{C}$. It can be observed that the QTMZNSbased sensor exhibits a short response-recovery time and low detection limit for the detection of formaldehyde. The response and recovery times were about $3 \mathrm{~s}$ and $6 \mathrm{~s}$ when the formaldehyde concentration was $0.2 \mathrm{ppm}$. For the semiconductor sensors, good selectivity is also a critical parameter and it is the ability of sensors to respond to a specific gas in presence of other gases. ${ }^{45}$ The target gases, such as ammonia, ethanol, acetone, formaldehyde, carbonic oxide, aether, benzene, 93\#petrol, methanol, and toluene were used to investigate the sensor selectivity at an optimal working temperature of $210^{\circ} \mathrm{C}$, where the concentration of all the testing gases was $50 \mathrm{ppm}$. It is can be seen clearly from Fig. 9(b), the sensor based on QTMZNS has a much higher response to formaldehyde than that to ethanol, methanol, acetone, carbonic oxide, benzene, 93\#petrol, toluene, and ammonia under fixed concentration. So the result indicates that the sensor based on the QTMZNS exhibited low detection limit, high sensitivity, great selectivity and a short response-recovery time for detection of 

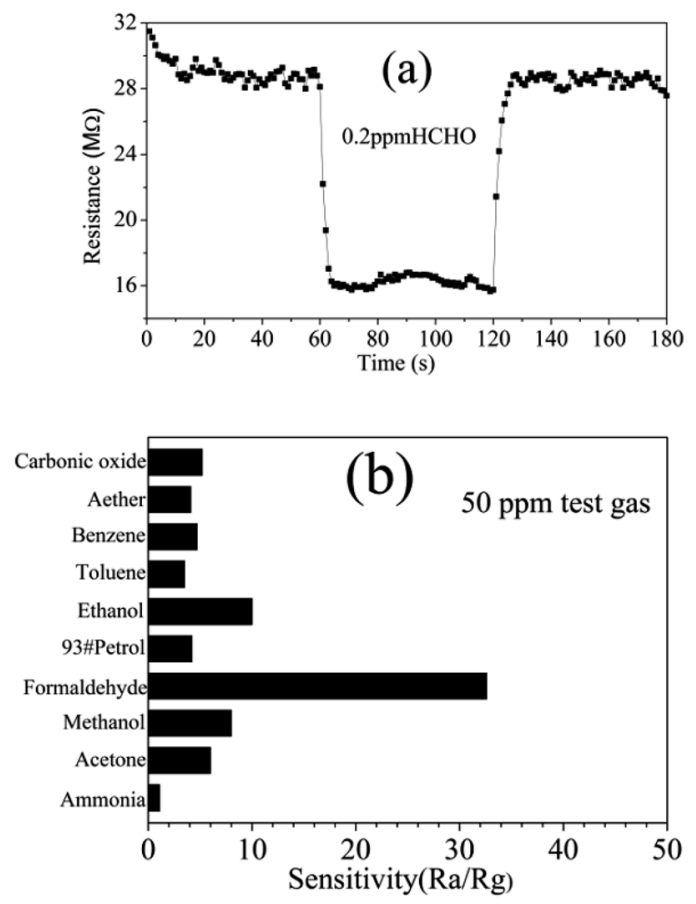

Fig. 9 (a) Response/recovery time graph of the QTMZNS-based sensor to $0.2 \mathrm{ppm}$ formaldehyde at $210{ }^{\circ} \mathrm{C}$. (b) Selectivity of the QTMZNS-based sensor to $50 \mathrm{ppm}$ different gases at $210^{\circ} \mathrm{C}$.

formaldehyde vapors at a low operating temperature of $210{ }^{\circ} \mathrm{C}$, which will have great potential in applications for practical air quality monitoring. To further consider the application value of the QTMZNS-based sensor, a comparison of the formaldehyde sensing ability of different $\mathrm{ZnSnO}_{3}$ materials between our work and previous literatures is listed in Table $1 .^{24-26,46-49}$ The response (45.8) of the QTMZNS to formaldehyde is higher than that of other $\mathrm{ZnSnO}_{3}$ materials. Moreover, the present sensor can detect $\mathrm{HCHO}$ sensing properties at $0.2 \mathrm{ppm}$, and such a lowconcentration formaldehyde gas test has not been reported so far to $\mathrm{ZnSnO}_{3}$ sensors.

\subsection{Sensing mechanism of QTMZNS}

For n-type $\mathrm{ZnSnO}_{3}$ material, the sensing mechanism that is widely accepted is the electrical conductivity taken place in the surface of the materials, which involves serial processes of adsorption-oxidation-desorption..$^{50,51}$ When QTMZNS are in the air, mass of oxygen molecules are adsorbed on the surface, and electrons from the surface of QTMZNS sensing layer are seized by lots of oxygen adsorbed, which can give rise to the transformation from oxygen species to oxygen ions $\left(\mathrm{O}^{-}\right)$at the operating temperature and the formation of electron depletion layers. As a result, the potential barriers are formed and the resistance is relatively high. After exposed to formaldehyde gas, the interaction occurs between formaldehyde gas and surface oxygen species and the electrons are released back into the sensing material, which results in a dramatic decrease in resistance. Therefore, an increase in surface area, chemisorbed oxygen and open nanoholes can improve the sensing performance. In this work, in order to better explain the outstanding gas-sensing properties for formaldehyde vapors at a relative low operating temperature of the QTMZNS-based sensor, both the BET specific surface area and a band gap of the QTMZNS were also investigated, and the result shows in Fig. 10. Nitrogen adsorption-desorption analysis of the QTMZNS (Fig. 10(a) and inset) reveals that the specific surface area using BET method is about $105.3 \mathrm{~m}^{2} \mathrm{~g}^{-1}$ and the average pore size of such a sample is about $7.9 \mathrm{~nm}$, which is corresponding with the SEM and TEM in Fig. 4. The specific surface area of the QTMZNS is bigger than that of other $\mathrm{ZnSnO}_{3}$ material, such as $\mathrm{ZnSnO}_{3}$ solid cubes (37 $\left.\mathrm{m}^{2} \mathrm{~g}^{-1}\right),{ }^{20} \mathrm{ZnSnO}_{3}$ nanosheets $\left(57.86 \mathrm{~m}^{2} \mathrm{~g}^{-1}\right),{ }^{21} \mathrm{ZnSnO}_{3}$ hollow microspheres $\left(30.21 \mathrm{~m}^{2} \mathrm{~g}^{-1}\right)$, ${ }^{22}$ porous $\mathrm{ZnSnO}_{3}$ hollow nanocube $\left(66.9 \mathrm{~m}^{2} \mathrm{~g}^{-1}\right),{ }^{23} \mathrm{ZnSnO}_{3}$ single-shelled cubes $\left(70 \mathrm{~m}^{2} \mathrm{~g}^{-1}\right)$, $\mathrm{ZnSnO}_{3}$ double-shelled cubes $\left(86 \mathrm{~m}^{2} \mathrm{~g}^{-1}\right), \mathrm{ZnSnO}_{3}$ multishelled cubes $\left(98 \mathrm{~m}^{2} \mathrm{~g}^{-1}\right),{ }^{24}$ mesoporous $\mathrm{ZnSnO}_{3}$ nanocrystals $\left(96 \mathrm{~m}^{2}\right.$ $\left.\mathrm{g}^{-1}\right),{ }^{27}$ and so on. This isotherm can be classified as type IV with an $\mathrm{H} 3$ type hysteresis loop which is characteristic for mesoporous materials. ${ }^{52}$ Fig. 10 (b) represents the UV-visible diffused reflectance spectra of the QTMZNS. The UV-visible diffused reflectance spectrum of QTMZNS shows absorption edge at $413 \mathrm{~nm}$ giving a band gap $\left(E_{\mathrm{g}}=h c / \lambda\right)$ value of $3.0 \mathrm{eV}$, which is the lowest than those of the previous reports about $\mathrm{ZnSnO}_{3}$ material. ${ }^{48,53}$ The decrease of band gap energy can be attributed to surface defects, and the defects might be the vacancies of oxygen/defects. As a result, the surface-related defects are the best condition to the absorption of $\mathrm{O}^{2-}$ and $\mathrm{O}^{-}$for gas detection. ${ }^{48,54,55}$ According to the $\mathrm{HCHO}$ sensing mechanism of $\mathrm{ZnSnO}_{3}$ above, the outstanding gas-sensing properties for formaldehyde vapors of the QTMZNS-based sensor were

Table 1 Comparison of formaldehyde sensing ability of different gas sensors based on $\mathrm{ZnSnO}_{3}$ materials

\begin{tabular}{|c|c|c|c|c|}
\hline Materials & HCHO concentration (ppm) & Working temperature $\left({ }^{\circ} \mathrm{C}\right)$ & Response $\left(R_{\mathrm{g}} / R_{\mathrm{a}}\right)$ & References \\
\hline $\mathrm{ZnSnO}_{3}$ porous cubes & 100 & 300 & 36.8 & 46 \\
\hline $\mathrm{ZnSnO}_{3}$ nanocages & 50 & 210 & $\sim 5$ & 47 and 48 \\
\hline $\mathrm{ZnSnO}_{3}$ solid cubes & 100 & 220 & 10.7 & 24 \\
\hline $\mathrm{ZnSnO}_{3}$ single-shelled cubes & 100 & 220 & 15.4 & 24 \\
\hline $\mathrm{ZnSnO}_{3}$ multishelled cubes & 100 & 220 & 37.2 & 24 \\
\hline $\mathrm{ZnSnO}_{3}$ quasi 2D nanomaterials & 100 & 210 & 45.8 & This work \\
\hline
\end{tabular}



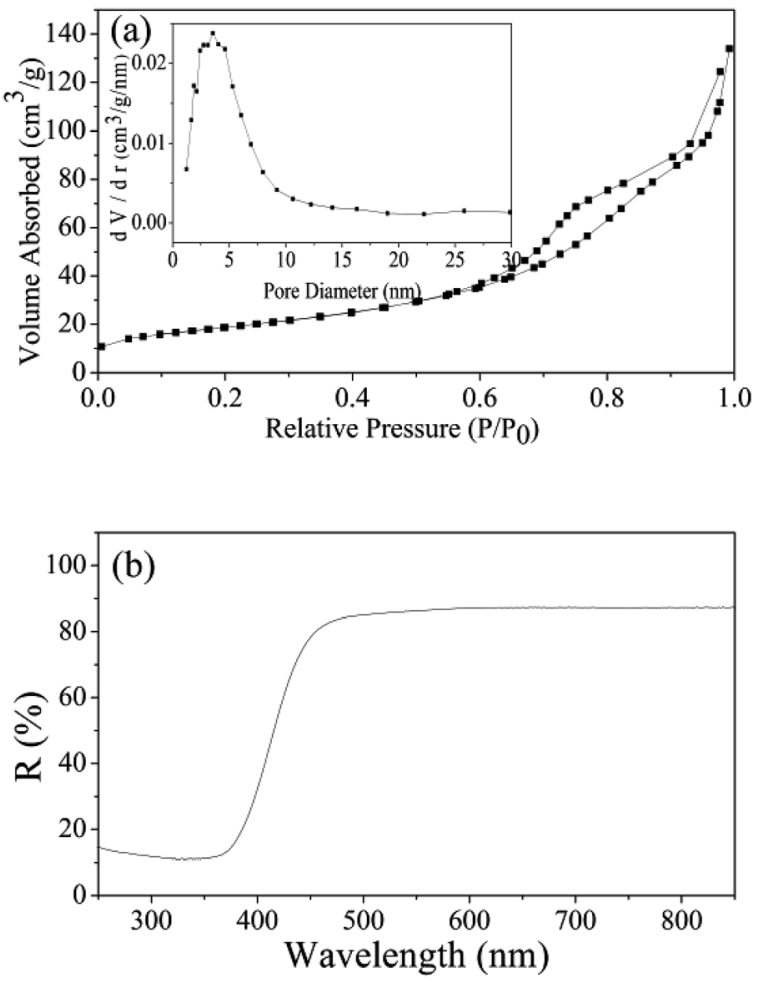

Fig. 10 (a) Nitrogen adsorption-desorption isotherms and pore size distribution curves (the inset), and (b) UV-visible DRS spectra of QTMZN.

attributed to the unique structure of the QTMZNS which have the following four advantages: (a) large specific surface area provides large contact area and void which can offer more chemical active sites. (b) Less band gap energy should help the $\mathrm{O}_{2}$ adsorption on the $\mathrm{ZnSnO}_{3}$ surface to trap electrons from the conduction band of $\mathrm{ZnSnO}_{3}$ and enhance the sensing performance. (c) Special open nanoholes can facilitate the adsorption of target gas and shorten gas diffusion path. (d) QTMZNS have been an aggregate assembled by nanoparticles, which endow the good stability compared with particles due to the decreased surface energies. Stable structure can ensure the stability of gas sensitive test results which can be seen in previous literatures. ${ }^{28,29}$ So, choosing QTMZNS as a sensitive material is a good choice for the detecting of HCHO.

\section{Conclusions}

In summary, the quasi two-dimensional mesoporous $\mathrm{ZnSnO}_{3}$ nanomaterials were synthesized by a simple template-free hydrothermal method combined with calcination and subsequent washing. The appearance of the quasi two-dimensional mesoporous structure was attributed to the decomposition of $\mathrm{ZnSn}(\mathrm{OH})_{6}$ and the formation of nanosheets $\mathrm{Zn}_{5}(\mathrm{OH})_{6}\left(\mathrm{CO}_{3}\right)_{2}$ in the hydrothermal process. The QTMZNS-based sensors exhibited outstanding performances towards formaldehyde, which are suitable for continuous and effective detection of formaldehyde. It is anticipated that the unique sensing properties of
QTMZNS make them a good potential material in the gas sensor field.

\section{Conflicts of interest}

There are no conflicts to declare.

\section{Acknowledgements}

We acknowledge the funding support from the National Natural Science Foundation of China (21661017 and 51602135), the Educational Supporting Projects of Jiangxi Province (GJJ171154 and GJJ160894), and the Science and Technology Program of Jingdezhen (2017GYZD018-01). We thank the Platforms of Characterization \& Test and Nanofabrication of National Engineering Research Center for Domestic \& Building Ceramics.

\section{References}

1 D. F. Hou, W. Luo, Y. H. Huang, J. C. Yu and X. L. Hu, Nanoscale, 2013, 5, 2028.

2 C. Z. Yuan, X. G. Zhang, L. H. Su, B. Gao and L. F. Shen, J. Mater. Chem., 2009, 19, 5772.

3 K. An and T. Hyeon, Nano Today, 2009, 4, 359.

4 W. Y. Li, L. M. Xu and J. Chen, Adv. Funct. Mater., 2005, 15, 851.

5 J. Gao, H. Y. Wu, J. Zhou, L. Y. Yao, G. Zhang, S. Xu, Y. Xie, L. Li and K. Y. Shi, New J. Chem., 2016, 40, 1306.

6 G. H. Li, X. W. Wang, H. Y. Ding and T. Zhang, RSC Adv., 2012, 2, 13018.

7 Q. Liu, L. Jiang and L. Guo, Small, 2014, 10, 48.

8 C. Qiu, L. Zhang, H. Wang and C. Y. Jiang, J. Phys. Chem. Lett., 2012, 3, 651.

9 N. Pinna, G. Neri, M. Antonietti and M. Niederberger, Angew. Chem., Int. Ed., 2004, 43, 4345.

10 P. Innocenzi, L. Malfatti and G. J. A. A. Soler-Illia, Chem. Mater., 2011, 23, 2501.

11 K. R. Prasad, K. Koga and N. Miura, Chem. Mater., 2004, 16, 1845.

12 Q. Dong, S. Yin, C. S. Guo, X. Y. Wu, N. Kumada, T. Takei, A. Miura, Y. Yonesaki and T. Sato, Appl. Catal., B, 2014, 147, 741.

13 H. Dai, Y. Zhou, L. Chen, B. L. Guo, A. D. Li, J. G. Liu, T. Yu and Z. G. Zou, Nanoscale, 2013, 5, 5102.

14 W. W. Lei, D. Portehault, D. Liu, S. Qin and Y. Chen, Nat. Commun., 2013, 4, 1777.

15 G. S. Gund, D. P. Dubal, D. S. Dhawale, S. S. Shinde and C. D. Lokhande, RSC Adv., 2013, 3, 24099.

16 W. W. Zhao, C. B. Liu, L. M. Cao, X. G. Yin, H. L. Xu and B. Zhang, RSC Adv., 2013, 3, 22944.

17 T. Minami, MRS Bull., 2000, 25, 38.

18 P. M. Rorvik, T. Grande and M. A. Einarsrud, Adv. Mater., 2011, 23, 4007.

19 A. Kafizas, S. Kellici, J. A. Darr and I. P. Parkin, J. Photochem. Photobiol., A, 2009, 204, 183.

20 T. T. Zhou, T. Zhang, R. Zhang, J. N. Deng, Z. Lou, G. Lu and L. L. Wang, Appl. Surf. Sci., 2017, 400, 262. 
21 Y. J. Chen, L. Yu, Q. Li, Y. Wu, Q. H. Li and T. H. Wang, Nanotechnology, 2012, 23, 415501.

22 X. H. Jiaa, M. G. Tian, R. R. Dai, D. D. Lian, S. Han, X. Y. Wu and H. H. Song, Sens. Actuators, B, 2017, 240, 376.

23 W. W. Guo, J. Electrochem. Soc., 2016, 163(5), 131.

24 T. T. Zhou, T. Zhang, R. Zhang, Z. Lou, J. N. Deng and L. L. Wang, ACS Appl. Mater. Interfaces, 2017, 9, 14525.

25 Y. F. Bing, Y. Zeng, C. Liu, L. Qiao, Y. M. Sui, B. Zou, W. T. Zheng and G. T. Zou, Sens. Actuators, B, 2014, 190, 370.

26 J. R. Huang, X. J. Xu, C. P. Gu, W. Z. Wang, B. Y. Geng, Y. F. Sun and J. H. Liu, Sens. Actuators, B, 2012, 171, 572.

27 S. Roy, B. Banerjee, A. Bhaumik and S. Islam, RSC Adv., 2016, 6, 31153.

28 J. Y. Liu, Z. Guo, F. L. Meng, T. Luo, M. Q. Li and J. H. Liu, Nanotechnology, 2009, 20, 125501.

29 L. X. Zhang, J. H. Zhao, H. Q. Lu, L. Li, J. F. Zheng, H. Li and Z. P. Zhu, Sens. Actuators, B, 2012, 161, 209.

30 L. L. Wang, T. Fei, Z. Lou and T. Zhang, ACS Appl. Mater. Interfaces, 2011, 3, 4689.

31 Y. H. Li, W. Luo, N. Qin, J. P. Dong, J. Wei, W. Li, S. S. Feng, J. C. Chen, J. Q. Xu, A. A. Elzatahry, M. H. EsSaheb, Y. H. Deng and D. Y. Zhao, Angew. Chem., Int. Ed., 2014, 53, 9035.

32 C. H. Zhao, J. C. Fu, Z. X. Zhang and E. Q. Xie, RSC Adv., 2013, 3, 4018.

33 J. Yang, L. Xue, J. Lang and L. Yang, Mater. Sci. Semicond. Process., 2011, 14, 247.

34 F. Y. Fan, P. G. Tang, Y. Y. Wang, Y. J. Feng, A. F. Chen, R. X. Luo and D. Q. Li, Sens. Actuators, B, 2015, 215, 231.

35 Z. D. Lin, F. Guo, C. Wang, X. H. Wang, K. Wang and Y. Qu, RSC Adv., 2014, 4, 5122.

36 F. Li, J. Jian, R. Wu, J. Li and Y. Sun, J. Alloys Compd., 2015, 645, 178.

37 Z. P. Xu, G. S. Stevenson and C. Q. Lu, J. Am. Chem. Soc., 2006, 128(1), 36.
38 Z. H. Jing and J. H. Zhan, Adv. Mater., 2008, 20(23), 4547.

39 J. Liu, X. C. Tang, Z. M. Wang and X. J. Yu, Chin. J. Inorg. Chem., 2012, 11(28), 2329.

40 J. H. Yang, X. Li, J. H. Lang, L. L. Yang and M. B. Wei, Mater. Sci. Semicond. Process., 2011, 14, 247.

41 L. X. Zhang, J. H. Zhao, H. Q. Lu and L. Li, Sens. Actuators, B, 2012, 161, 209.

42 W. W. Guo, T. M. Liu, Z. P. Gou and W. Zeng, J. Mater. Sci.: Mater. Electron., 2013, 24(6), 1764.

43 F. L. Meng, N. N. Hou, Z. Jin, B. Sun and Z. Guo, Sens. Actuators, B, 2015, 209, 975.

44 T. V. Dang, N. D. Hoa, N. V. Duy and N. V. Hieu, ACS Appl. Mater. Interfaces, 2016, 8, 4828.

45 P. Song, Q. Wang and Z. X. Yang, Sens. Actuators, B, 2011, 156, 983.

46 Y. Zeng, T. Zhang, H. T. Fan, W. Y. Fu, G. Y. Lu, Y. M. Sui and H. B. Yang, J. Phys. Chem. C, 2009, 113, 19000.

47 Y. Zeng, T. Zhang, H. T. Fan, G. Y. Lu and M. H. Kang, Sens. Actuators, B, 2009, 143, 449.

48 Z. J. Wang, J. Liu, F. J. Wang, S. Y. Chen, H. Luo and X. B. Yu, J. Phys. Chem. C, 2010, 114, 13577.

49 J. Q. Xu, X. H. Jia, X. D. Lou, G. X. Xi, J. J. Han and Q. H. Gao, Sens. Actuators, B, 2007, 120, 694.

50 L. Wang, J. A. Jackman, W. B. Ng and N. J. Cho, Adv. Funct. Mater., 2016, 26, 8623.

51 N. Barsan and U. Weimer, J. Electroceram., 2001, 7, 143.

52 M. Pramanik, M. Nandi, H. Uyama and A. Bhaumik, Catal. Sci. Technol., 2012, 2, 613.

53 A. V. Borhade and Y. R. Baste, Arabian J. Chem., 2017, 10, 404. 54 J. Gao, L. L. Wang, K. Kan, S. Xu, L. Q. Jing, S. Q. Liu, P. K. Shen, L. Li and K. Y. Shi, J. Mater. Chem. A, 2014, 2, 949.

55 E. Carter, A. F. Carley and D. M. Murphy, J. Phys. Chem. C, 2007, 111(28), 10630. 